\title{
15th International Workshop on Advanced Infrared Technology and Applications (AITA) ${ }^{\dagger}$
}

\author{
Paolo Bison ${ }^{1}$, Mario D'Acunto ${ }^{2}$, Xavier Maldague ${ }^{3}$, Davide Moroni ${ }^{4} * \mathbb{D}$, Valentina Raimondi ${ }^{5}$, \\ Antoni Rogalski ${ }^{6}$, Takahide Sakagami ${ }^{7}$ and Marija Strojnik ${ }^{8}$ \\ 1 Istituto per le Tecnologie della Costruzione, CNR, 35127 Padova, Italy; paolo.bison@itc.cnr.it \\ 2 Istituto di Biofisica, CNR, 56124 Pisa, Italy; mario.dacunto@pi.ibf.cnr.it \\ 3 Electrical and Computer Engineering Department, Université Laval, Quebec, QC G1V 0A6, Canada; \\ maldagx@gel.ulaval.ca \\ 4 Istituto di Scienza e Tecnologie dell'Informazione "Alessandro Faedo", CNR, 56124 Pisa, Italy \\ 5 Istituto di Fisica Applicata "Nello Carrara", CNR, 50019 Sesto Fiorentino FI, Italy; v.raimondi@ifac.cnr.it \\ 6 Institute of Applied Physics, Military University of Technology, 01-476 Warsaw, Poland; \\ antoni.rogalski@wat.edu.pl \\ 7 Department of Mechanical Engineer, Kobe University, Kobe 657-8501, Japan; sakagami@mech.kobe-u.ac.jp \\ 8 Centro de Investigaciones en Óptica (CIO), 37150 León, Mexico; mstrojnik@gmail.com \\ * Correspondence: davide.moroni@isti.cnr.it \\ + Presented at the 15th International Workshop on Advanced Infrared Technology and Applications (AITA \\ 2019), Florence, Italy, 17-19 September 2019.
}

Published: 16 December 2019

check for

Abstract: The 15th International Workshop on Advanced Infrared Technology and Applications has been held in Florence on 16-19 September 2019.

Keywords: Infrared imaging; Smart and fiber-optic sensors; Thermo-fluid dynamics; Biomedical applications; Environmental monitoring; Aerospace and industrial applications; Nanophotonics and nanotechnologies; Astronomy and Earth observation; Non-destructive tests and evaluation; Systems and applications for the cultural heritage

\section{Introduction}

The 15th International Workshop on Advanced Infrared Technology and Applications has been organized by the Fondazione "Giorgio Ronchi", the Istituto di Fisica Applicata "Nello Carrara" (IFAC-CNR), the Istituto per le Tecnologie delle Costruzioni (ITC-CNR), the Istituto di Scienza e Tecnologie dell'Informazione "Alessandro Faedo" (ISTI-CNR) and the Istituto di Biofisica (IBF-CNR).

After having organized the 13th edition in Pisa in 2015, AITA conference moved to North America with the 14th edition that was hosted at Laval University (Quebec City) in September 2017 under the organisation of the Canada Research Chair on Multipolar Infrared Vision Infrarouge Mulipolaire (MIVIM) of the Electrical and Computer Engineering Department.

In 2019, AITA came back again to Italy and, more precisely, to Florence, where the idea of this conference series spurred about 25 years ago mainly thanks to the efforts and commitment by the Fondazione "Giorgio Ronchi". In addition, 2019 is a special year since it marks an important anniversary: the 90th birthday of Prof. Laura Ronchi Abbozzo, AITA General Chair, to which the workshop has been dedicated.

The workshop program featured a technical seminar day (Section 2) followed by actual conference days (Section 3). A selection of the received papers will be published in a peer-review journal, namely OSA Applied Optics. 
AITA scientific program was accompanied by two social events, namely a visit to the Cenacolo del Fuligno, featuring a masterpiece fresco by the Italian Renaissance painter Pietro Perugino (Figure 1), and a Gala Dinner in a traditional Florentine restaurant.

Finally, the website http://ronchi.isti.cnr.it/AITA2019 will be maintained active for future references.

The 16th International Workshop on Advanced Infrared Technology and Applications will take place in Venice, Italy, in late summer/fall 2021.

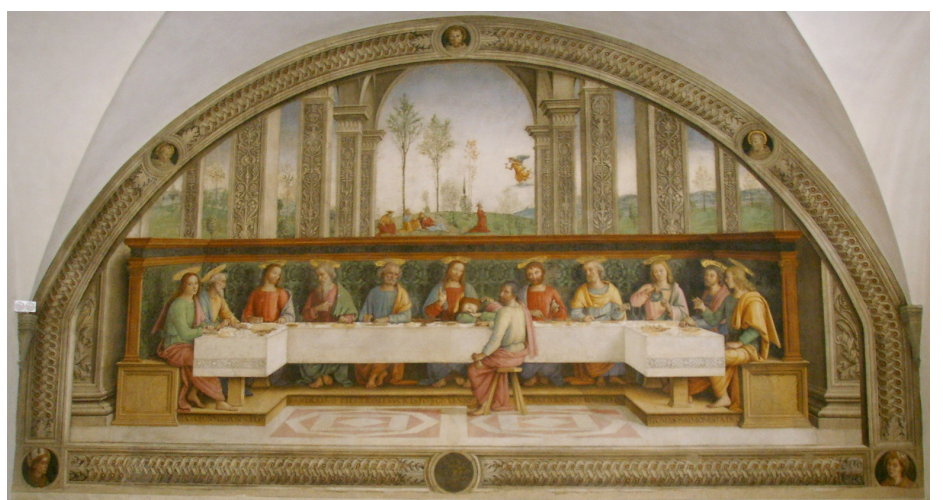

Figure 1. The Last Supper (1493-1496), a fresco by the Italian Renaissance painter Pietro Perugino, located in the refectory of the former Convent of Fuligno (picture by Sailko available in Wikimedia under CC BY-SA 3.0).

\section{Technical Seminar: Infrared Techniques and Applications for Aerospace}

Florence and Tuscany Region enjoy a long tradition in optics and space optics, and still today photonics and space technologies are included in the smart specialisation strategy of the Tuscany region. For this reason, the AITA organising committee has decided to dedicate to this sector a technical seminar titled "Infrared techniques and applications for aerospace".

The one-day seminar has been held on September 16 and has been organised as an Open Engagement Event by the INTERREG Europe project STEPHANIE led by the Istituto di Fisica Applicata "Nello Carrara" (IFAC-CNR) with Tuscany Region as a key partner.

Twelve talks were delivered by invited speakers who discussed extensively key challenges, trends and opportunities for the aerospace sector, discussing several Earth Observation applications ranging from climate to volcano monitoring, from oceanography to smart cities.

\section{Conference Days}

The actual conference days run from September 17 to September 19 at noon. The technical program was organized in 13 sessions on the following topics: Image Processing and data analysis; Advanced technology and materials; Non-destructive testing; Biomedical Applications and Spectroscopy; Astronomy, Earth observation and environment; Cultural Heritage; Aerospace and industrial applications.

Sessions of general interest were organised as plenary, while due to the limited available time, some more specialist sessions have been run in parallel.

Highlights from the program include four keynote speeches that were distributed along the conference days. After the opening session on September 17, Prof. Elżbieta Pieczyska gave an introduction to a new Ti alloy - Gum Metal, describing new results obtained thanks to the infrared technique. On September 18, we had a morning keynote speech by Xavier Maldague, who provided an interesting review of inspection methodologies based on infrared thermography by drones, and an afternoon talk by Dr.ssa Carosena Meola, who surveyed the contribution of infrared thermography within impact testing of composite materials. Finally on the last conference day, Prof. Marija Strojnik gave a speech on rotationally shearing interferometry for extrasolar planet detection, accounting a 
joint work with Beethoven Bravo-Medina. A further highlight is represented by the technical and vendor session that took place on September 17 after lunch. On this occasion, vendors were allowed to give a presentation of their top and innovative instruments by either discussing the opportunities offered to the scientific community and describing their successful applications.

A total of 54 papers were presented and will be included in the workshop proceedings, published in MDPI Proceedings, vol. 27 (https:/ /www.mdpi.com/2504-3900/27/1).

\section{4th under-35 Paper Award}

A best paper award has been assigned by the chairpersons in honour of Ermanno Grinzato, AITA co-chairman for a long time and known scientist in the thermography community. The award aims at encouraging innovative studies of young researchers in some of the topics of interest for the workshop.

In view of the excellent talks delivered by young scientists, this year the commission decided to give an ex aequo prize to Chiara Filippini for the paper "Thermal imaging based affective computing for educational robot" [1] and to Klaudia Hackiewicz for the paper "InAs/GaSb superlattice based mid-infrared interband cascade photodetectors grown on both native GaSb and lattice-mismatched GaAs substrates" [2].

An honorable mention was also awarded to Raffael Thiessen for the paper "Infrared Thermography and DIT of Quadcopter Rotor Blades Using Laser Heating" [3].

\section{Committes}

General chair

L. Ronchi Abbozzo Fondazione Giorgio Ronchi, Firenze, Italy

Co-chair

P. Bison

M. D'Acunto

X. Maldague

D. Moroni

V. Raimondi

A. Rogalski

T. Sakagami

M. Strojnik

Scientific committee

B. Allotta

D. Balageas

C. Corsi

E. Dereniak

C.T. Elliott

C. Maierhofer

C. Meola

H.N. Rutt

O. Salvetti

G. Steenackers

J.L. Tissot

V.P. Vavilov

M. Volinia

H. Zogg

ITC-CNR, Padova, Italy

IBF-CNR, Pisa, Italy

Laval University, Quebec, Canada

ISTI-CNR, Pisa, Italy

IFAC-CNR, Firenze, Italy

Military University of Technology, Warsaw, Poland

Kobe University, Kobe, Japan

CIO, León, Guanajuato, Mexico

University of Firenze, Firenze, Italy

ONERA, Chatillon, France

Alenia-Creo, L'Aquila, Italy

University of Arizona, Tucson, USA

Heriot-Watt University, Edinburgh, Scotland

BAM, Germany

University of Napoli, Napoli, Italy

Southampton University, Southampton, United Kingdom

ISTI-CNR, Pisa, Italy

University of Antwerp, Antwerp, Belgium

ULIS, Veurey Voroize, France

Tomsk University, Tomsk, Russia

Politecnico of Torino, Torino, Italy

ETH, Zurich, Switzerland 
Program committee
G. Cadelano
ITC-CNR, Italy
A. Carboni
ISTI-CNR, Italy
S. Colantonio
ISTI-CNR, Italy
G. Ferrarini
ITC-CNR, Italy
D. Germanese
ISTI-CNR, Italy
D. Guzzi
IFAC-CNR, Italy
B. Jalil
ISTI-CNR, Italy
C. Lastri
IFAC-CNR, Italy
M.A. Pascali
ISTI-CNR, Italy
G. Pieri
ISTI-CNR, Italy
M. Reggiannini
ISTI-CNR, Italy
A. Scozzari
ISTI-CNR, Italy
A. Tonazzini
ISTI-CNR, Italy
Organizing committee
F. Pardini
M. Tampucci
E. Ricciardi
ISTI-CNR, Italy
ISTI-CNR, Italy
Comitato Organizzazione di Conferenze ed Eventi Scientifici (COCES), Italy

Acknowledgments: We would like to thank the Associazione Italiana Prove non Distruttive Monitoraggio Diagnostica (AIPnD) for the patronage of our event and the INTERREG Europe project STEPHANIE (Space TEchnology with PHotonics for market and societal challenges) for having sponsored the technical seminar. We also thank our sponsors FLIR, InfraTec, ThermoFisher Scientific and Telops for generous support. We are grateful to all the members of the scientific committee and of the program committee that helped the chairpersons in the reviewing process, providing timely, professional and constructive comments that fostered the scientific quality of AITA workshop. A special note is reserved to Ovidio Salvetti which gave us precious suggestions and advice in organising this scientific event and to Benedetto Allotta, who helped us in finding a suitable venue in Florence. Special thanks go to our treasurer Ettore Ricciardi, to Marco Tampucci, who served as the webmaster, and, finally, to Francesca Pardini, who took care of organisational aspects in a tireless way and make it possible to have a successful workshop edition.

Conflicts of Interest: The authors declare no conflict of interest.

\section{References}

1. Filippini, C.; Spadolini, E.; Cardone, D.; Merla, A. Thermal Imaging Based Affective Computing for Educational Robot. Proceedings 2019, 27, 27, doi:10.3390/proceedings2019027027.

2. Hackiewicz, K.; Kopytko, M.; Rutkowski, J.; Martyniuk, P.; Ciura, Ł. InAs/GaSb Superlattice Based Mid-Infrared Interband Cascade Photodetectors Grown on Both Native GaSb and Lattice-Mismatched GaAs Substrates. Proceedings 2019, 27, 38, doi:10.3390/proceedings2019027038.

3. Thiessen, R.; Schülein, E. Infrared Thermography and DIT of Quadcopter Rotor Blades Using Laser Heating. Proceedings 2019, 27, 31, doi:10.3390/proceedings2019027031.

(C) 2019 by the authors. Licensee MDPI, Basel, Switzerland. This article is an open access article distributed under the terms and conditions of the Creative Commons Attribution (CC BY) license (http://creativecommons.org/licenses/by/4.0/). 